\title{
О некоторых проблемах борьбы с религиозным экстремизмом В уголовно-испонительной системе Российской Федерации
}

В. В. ХРУЛЕВА - доцент кафедры теории и истории государства и права
Воронежского института МВД России, кандидат юридических наук, доцент;

и. С. МАСлов - преподаватель кафедры теории и истории государства и права Воронежского института МВД России

Реферат

В статье рассматриваются вопросы распространения религиозного экстремизма и противодействия ему в системе исполнения наказаний Российской Федерации. Приводится соотношение различных точек зрения ученых по данной теме. Анализируются особенности нормативно-правового регулирования конституционного права на свободу вероисповедания и деятельности государства по профилактике распространения религиозного экстремизма в пенитенциарной системе России. Освещаются проблемы вербовочного процесса новых членов экстремистских и террористических организаций и распространения деструктивных религиозных учений. Проводится анализ причин и последствий проникновения данных организаций в пенитенциарные учреждения. Обращается внимание на специфику развития религиозного экстремизма с учетом влияния норм криминального поведения на заключенных, приводятся примеры негативного влияния деструктивных религиозных организаций на лиц, отбывающих наказание, и последующего совершения ими противоправных действий. Раскрываются особенности взаимодействия сотрудников пенитенциарной системы с лицами, осужденными за совершение преступлений экстремистского и террористического характера.

К л ю че в ы е с ло в а: пенитенциарная система Российской Федерации; тоталитарная секта; деструктивная религиозная организация; религиозный экстремизм; национальная безопасность Российской Федерации.

12.00.08 - Уголовное право и криминология; уголовно-исполнительное право 


\title{
On some problems of fight against religious extremism in the penal system of the Russian Federation
}

\author{
V. V. KHRULEVA - Associate Professor of Theory and History of State and Law \\ of the Voronezh Institute of the Ministry of Internal Affairs of Russia, PhD. in Law, \\ Associate Professor;
}

I. S. MASLOV - Lecturer of the Department of Theory and History of State and Law of the Voronezh Institute of the Ministry of internal Affairs of Russia

\begin{abstract}
The article is devoted to the spread of religious extremism and its counteraction in the penal system of the Russian Federation. The ratio of different points of view of theorists on the topic of religious extremism is given. The article deals with the peculiarities of the legal regulation of the constitutional right to freedom of religion and the activities of the state to prevent and combat the spread of religious extremism in the penal system of Russia. The article highlights the problem of recruitment of new members of extremist and terrorist organizations and the spread of destructive religious teachings. The analysis of the causes and consequences of the penetration of destructive religious organizations into the penal institutions of the Russian Federation is carried out. Attention is drawn to the specifics of the development of religious extremism characteristic of the penal system of Russia, taking into account the impact of norms of criminal behavior on prisoners. The duality of influence of religion as positive character is reflected, so examples of negative influence of the destructive religious organizations on persons serving punishment and the subsequent commission of illegal actions by them are given. The article deals with the issues that reveal the features of the activities of prison staff with persons convicted of crimes of extremist and terrorist nature. The possible ways of their solution, which the staff of the penal system have to face in their daily activities are given.

Key words: penal system of the Russian Federation; totalitarian sect; destructive religious organization; religious extremism; national security of the Russian Federation.
\end{abstract}

12.00.08 - Criminal law and criminology; penal law

Распространение религиозного экстремизма является одним из проблемных вопросов в современном мире.

В начале XX в. экстремистами французский политолог М. Лерой назвал представителей политических партий или групп, объединившихся на основе веры и фанатично преданных своим идеям, ради воплощения которых готовых пожертвовать всем и всеми, в том числе и жизнью [2, с. 1].

Согласно толковому словарю С. И. Ожегова экстремизм - это приверженность в политике к крайним взглядам и мерам [8]. Экстремизм порождают различные факторы: слом сложившихся социальных структур, обнищание массовых групп населения, экономический и социальный кризис, ослабление государственной власти и дискредитация ее институтов, рост антисоциальных проявлений и др.

Для России религиозный экстремизм это угроза обществу и государству в целом, поскольку он стремится к радикальному изменению общепринятых канонов.

В настоящее время в российском законодательстве отсутствует четкое толкование понятия «религиозный экстремизм».
М. П. Новиков считает, что это идеология и деятельность крайне фанатичных элементов в религиозной организации. А. Я. Анцупов и А. И. Шипилов дают более развернутое толкование: «религиозный экстремизм - это стремление к крайним взглядам, стремление наиболее фанатичных групп верующих, руководителей и активистов религиозных организаций, а также околоцерковных кругов любыми методами, в том числе противозаконными, затормозить кризисные процессы, протекающие в том или ином культе, добиться определенных целей» [1, с. 493]. Одни ученые рассматривают религиозный экстремизм как результат действий разнообразных антироссийских сил - от зарубежных спецслужб до радикальных религиозных и квазирелигиозных новообразований, другие изучают его сквозь призму внутренних причин самого государства, например таких, как социально-экономический кризис государства, низкий уровень духовного развития населения, культура воспитания граждан и др.

Можно согласиться с точкой зрения С. С. Оганесяна, который обращает внимание на то, что на разных исторических эта- 
пах проявление экстремизма в той или иной степени характерно для всех религиозных учений, поэтому проблема религиозного экстремизма будет всегда актуальна [6, с. 6].

На возникновение религиозного экстремизма влияют в первую очередь те социально-профессиональные и демографические группы, которые в современных условиях по различным причинам не способны к полноценной реализации. Не только социальная и личностная неудовлетворенность, но и низкий культурный уровень, отсутствие прочных мировоззренческих основ, духовно-нравственные изъяны, эгоистические устремления и амбиции становятся источниками формирования религиозного экстремизма. Кроме маргиналов в качестве групп риска можно рассматривать молодежь, творческую интеллигенцию, работников коммерческо-банковской сферы и сферы обслуживания [3].

В соответствии со ст. 14 Конституции Российской Федерации наше государство является светским и ни одна из религий не может быть установлена в качестве обязательной или государственной, запрещается создание и деятельность общественных объединений, цели или действия которых направлены на насильственное изменение основ конституционного строя и нарушение целостности Российской Федерации, подрыв безопасности государства, создание вооруженных формирований, разжигание социальной, расовой, национальной и религиозной розни (ч. 5 ст. 13), запрещаются также любые формы ограничения прав граждан по признакам социальной, расовой, национальной, языковой или религиозной принадлежности (ч. 2 ст. 19), пропаганда или агитация, возбуждающие социальную, расовую, национальную или религиозную ненависть и вражду, а также пропаганда социального, расового, национального, религиозного или языкового превосходства (ч. 2 ст. 29). Следовательно, гражданам должен быть предоставлен равный доступ к различным религиозным организациям, которые осуществляют законную деятельность на территории Российской Федерации. Однако в целях обеспечения своей национальной безопасности государство не может совсем оставить без внимания их деятельность, что получило официальное регулирование на конституционном уровне. Соблюдение данного баланса - трудная задача для любого многонационального государства. Этим обстоятельством и пользуются деструктивные религиозные организации.
Свобода действий, предоставленная таким организациям, открывает перед их руководителями возможность действовать с целью получения исключительно политических, экономических и криминальных выгод, а не достижения каких-либо религиозных целей и нравственного развития верующих.

В целях упорядочения общественных отношений в этой области действует Федеральный закон от 25.07.2002 № 114-Ф3 «О противодействии экстремистской деятельности», в соответствии с которым созданы условия, препятствующие проникновению деструктивных религиозных организаций в учреждения исполнения наказаний.

Вместе с тем проблема распространения религиозного экстремизма продолжает нарастать.

Е. Э. Ганаева отмечает, что немаловажное значение имеет механизм вовлечения в религиозную экстремистскую деятельность. Именно здесь имеет место целенаправленное пропагандистское воздействие как на отдельных людей, так и целые социальные группы при попустительстве общественных и государственных институтов. При этом различные факторы материального, социально-политического, культурноидеологического и личностно-психологического характера делают такое воздействие максимально эффективным. Всегда нужно учитывать такую особенность, как изначальная предрасположенность некоторых лиц к восприятию экстремистской пропаганды вследствие характера воспитания, личностных особенностей, психоэмоционального состояния субъекта [3].

В пенитенциарной системе данная проблема является одной из самых актуальных.

Часть 1 ст. 14 УИК РФ закрепляет, что осужденному гарантируется свобода совести и вероисповедания, а также право исповедовать любую религию. Ему разрешается распространять свои религиозные убеждения и действовать в соответствии с ними. В ст. 118 УИК РФ предусмотрена дозволительная норма о том, что по просьбе осужденного, находящегося в помещении штрафного изолятора, возможно приглашение священнослужителя, который должен относиться к религиозным объединениям, зарегистрированным в установленном порядке.

В соответствии с положениями Стратегии национальной безопасности Российской Федерации, утвержденной указом Президента Российской Федерации от 31.12.2005 № 683, к основным источникам угроз национальной безопасности государства от- 
носятся националистические, религиозные, этнические организации, осуществляющие экстремистскую деятельность, которая направлена на изменение конституционного строя, дестабилизацию внутриполитической ситуации в России, а также нарушение территориальной целостности и единства страны.

Чем же опасна вербовочная деятельность деструктивных религиозных организаций для пенитенциарной системы России? Особенно остро стоит вопрос по тоталитарным сектам иностранного происхождения и деструктивным религиозным организациям, искажающим духовные ценности традиционного ислама. Опасность деятельности данных организаций заключается в том, что происходит вербовка людей с криминальным прошлым, которые в дальнейшем в большинстве своем должны возвратиться в социум. После вовлечения осужденного в ряды деструктивной религиозной организации он не имеет, по сути, реальной возможности добровольно покинуть религиозную организацию и прекратить членство в ней, что уже несет возможные негативные последствия для его близких и родных.

Говоря об участии традиционных религиозных организаций в жизнедеятельности уголовно-исполнительной системы Российской Федерации, следует отметить положительное влияние религии на формирование правомерного поведения и правосознания у осужденных. Однако известны факты, когда члены деструктивных религиозных организаций, камуфлируясь под традиционные для российского общества конфессии, использовали свое положение для передачи запрещенных предметов. Нередки случаи активного участия псевдослужителей культа в вербовочном процессе.

На проблему вербовки заключенных в экстремистские и террористические организации деструктивного характера пристальное внимание российские ученые обратили только в 2012 г. Возможно, это связано с планомерной работой правоохранительных органов и органов государственной безопасности по привлечению виновных лиц к юридической ответственности за осуществление экстремистской и террористической деятельности. Однако, по мнению В. В. Иванова и Р. Р. Сулейманова, массовое вовлечение осужденных в экстремистские организации приходится на 2010 г. В литературе отмечается, что «по результатам изучения личных данных новообращенных сторонников радикального ис- лама, объявленных правоохранительными органами в розыск за совершение экстремистских преступлений, около 8 процентов из 100 обработанных биографий показали, что люди приняли на веру деструктивные религиозные убеждения, находясь в местах лишения свободы» [7, с. 114]. Чаще всего в организации деятельности экстремистских организаций в учреждениях пенитенциарной системы активное участие принимают лица, прошедшие обучение канонам ислама за рубежом.

По мнению сотрудников пенитенциарной системы России, в настоящее время наряду с так называемыми черными, красными зонами распространены и «зеленые» зоны, в которых лидеры радикально настроенных общин (джамаатов) занимаются активным вербовочным процессом [6, с. 4].

Ярким свидетельством такой деятельности может служить пример задержания мужчины, планировавшего совершить террористический акт на территории г. Вологды, приведя в действие взрывное устройство. По данным следствия, мужчина стал последователем радикального течения ислама после знакомства в местах лишения свободы с вербовщиками, которые были осуждены за совершение преступлений террористического характера и отбывали уголовное наказание в исправительном учреждении Архангельской области. Кроме того, 9 июля 2013 г. Главное управление МВД России по Приволжскому федеральному округу возбудило уголовное дело по ч. 2 ст. 282.2 УК РФ в отношении М. Б. Муфтия, возглавлявшего центральное духовное управление мусульман Ульяновской области в составе Совета муфтиев России. Муфтия обвинили в том, что он принимал активное участие в деятельности тюремной ячейки террористической организации «Имарат Кавказ», созданной на территории исправительной колонии № 2 г. Новоульяновска. Развития это дело не получило за истечением срока давности, однако его расследование выявило интересные детали: тюремный джамаат был создан при активном участии духовного лидера банды «Ульяновский джамаат» В. И. Чуваша. Эта организованная преступная группировка промышляла разбоями и убийствами, параллельно ведя пропаганду ваххабизма. C 2001 г. более 20 имамов Совета муфтиев России были привлечены к уголовной ответственности за экстремизм и терроризм, причем только в 2015 г. один из них был осужден за пособничество ИГИЛ (Мордовия), другой арестован как вербов- 
щик ИГИЛ и владелец внушительного арсенала (Белгород), а третий уехал в Сирию воевать на стороне террористов (Воронеж). Как показывает практика, даже официальный статус духовного лидера не дает никаких гарантий, но облегчает доступ к местам лишения свободы вербовщикам [4, с. 112].

Уголовно-исполнительная система должна иметь в своем арсенале эффективный инструментарий противодействия представителям деструктивных религиозных течений. Даже при провозглашении принципа свободы вероисповедания следует избирательно подходить к допущению различного рода религиозных организаций к работе по исправлению осужденных, так как деятельность многих из них может привести к диаметрально противоположным последствиям и представлять значительную опасность для общества.

Некоторые адепты сект, оказавшись в учреждениях уголовно-исполнительной системы, продолжают совершать ритуальные действия, предусмотренные соответствующими псевдорелигиозными нормами. В этой связи при решении вопроса о допущении к работе с осужденными религиозных организаций одинаковый подход ко всем религиозным конфессиям представляется недопустимым [5].

В целях осуществления профилактики и противодействия политико-религиозному экстремизму в пенитенциарной системе России целесообразно:

- осуществлять дополнительный контроль за осужденными, поступившими в места лишения свободы, которые целенаправленно совершают незначительные общеуголовные преступления для организации в пенитенциарной системе агитационной и вербовочной деятельности, и проводить с этой категорией заключенных индивидуальновоспитательную работу;
- осуществлять меры по обучению сотрудников пенитенциарной системы в области религиозных знаний (особенно начальников отрядов, воспитателей, психологов и других должностных лиц, которые непосредственно работают с лицами, осужденными за религиозный терроризм и экстремизм);

- проводить совместную работу с органами государственной безопасности и правоохранительными органами по контролю за деятельностью иностранных миссионеров на территории Российской Федерации и непосредственно в учреждениях ФСИН РОссии;

- организовывать планомерную индивидуальную работу с каждым осужденным за совершение преступлений экстремистской направленности по его возвращению к традиционной форме исповедования религии, тем самым формировать у него мировоззрение веротерпимости и послушания, в том числе законам Российской Федерации;

- анализировать социально-экономические предпосылки возникновения политико-религиозного экстремизма на территории как Российской Федерации в целом, так и каждого субъекта в частности;

- более активно работать во взаимодействии с традиционными религиозными организациями России.

Таким образом, перед пенитенциарной системой стоят задачи по выработке научно-методологической основы, подкрепленной законодательной базой, в совокупности способной изменить сложившуюся ситуацию коренным образом. Именно благодаря слаженной и конструктивной работе государства, общества и традиционных религиозных организаций в Российской Федерации получится сформировать нравственно-духовное мировоззрение, способное сдержать любые попытки дестабилизировать мир и порядок в стране.

\section{СПИСОК ЛИТЕРАТУРЫ}

1. Анцупов, А. Я. Словарь конфликтолога / А. Я. Анцупов, А. И. Шипилов. - 2 изд. - Санкт-Петербург : Питер, 2006. - 528 с. - ISBN 978-5-699-38468-6.

2. Борьба с религиозным экстремизмом и терроризмом в современном обществе и России. URL: https://proreligiu. club/obshestvo/istoriya/borba-s-religioznym-ekstremizmom.html (дата обращения: 02.04.2019).

3. Ганаева, Е. Э. Религиозный экстремизм в России: проблемы теоретической интерпретации / Е. Э. Ганаева // Молодой ученый. - 2016. - № 1. - С. 795-797. URL: https://moluch.ru/archive/105/24905/ (дата обращения: 11.04.2019).

4. Матвеев, Д. О. Роль традиционных конфессий в профилактике религиозного экстремизма в учреждениях уголовно-исполнительной системы / Д. О. Матвеев // Вестник Московского университета МВД России. - 2014. № 3. - C. 111-114

5. Морозов, А. С. Псевдорелигиозная организация как субъект уголовно-исполнительных правоотношений / А. С. Морозов // Вестник Кузбасского института ФСИН России. - 2015. - № 3 (24). - С. 75-81.

6. Оганесян, С. С. Проблемы противодействия религиозному экстремизму и пути формирования веротерпимости в местах лишения свободы : монография / С. С. Оганесян, А. Ш. Габараев, О. Г. Годованец, П. Н. Казберов ; под научной редакцией С. С. Оганесяна. - Москва : НИИИТ ФСИН России, 2017. - 168 с. - ISBN 978-5-9632-0115-2.

7. Силантьев, Р. А. К проблеме вербовочной деятельности террористических и экстремистских организаций в местах лишения свободы / Р. А. Силантьев, В. В. Носков, А. В. Савин // Человек: преступление и наказание. 2017. - T. 25. - № 1. - C. 113-117.

8. Экстремизм. URL : http://www.endic.ru/ozhegov/JEkstremizm-40160.html (дата обращения: 02.04.2019). 


\section{REFERENCES}

1. Ancupov A. YA., SHipilov A. I. Slovar' konfliktologa [Conflictologists Dictionary]. St. Petersburg, 2006. 528 p. (In Russ.). 2. Bor'ba s religioznym ekstremizmom i terrorizmom v sovremennom obshchestve i Rossii [The fight against religious extremism and terrorism in modern society and Russia]. Available at: https://proreligiu.club/obshestvo/istoriya/borba-sreligioznym-ekstremizmom.html (accessed 02.04.2019). (In Russ.).

3. Ganaeva E. E. Religioznyj ekstremizm v Rossii: problemy teoreticheskoj interpretacii [Religious extremism in Russia: problems of theoretical interpretation]. Molodoj uchenyj - Young scientist, 2016, no. 1, pp. 795-797. Available at: https:// moluch.ru/archive/105/24905/ (accessed 11.04.2019). (In Russ.).

4. Matveev D. O. Rol' tradicionnyh konfessij v profilaktike religioznogo ekstremizma v uchrezhdeniyah ugolovno-ispolnitel'noj sistemy [The role of traditional faiths in the prevention of religious extremism in penal institutions]. Vestnik Moskovskogo universiteta MVD Rossii - Bulletin of the Moscow University of the Ministry of Internal Affairs of Russia, 2014, no. 3, pp. 111-114. (In Russ.)

5. Morozov A. S. Psevdoreligioznaya organizaciya kak sub»ekt ugolovno-ispolnitel'nyh pravootnoshenij [Pseudo-religious organization as a subject of penal relations]. Vestnik Kuzbasskogo instituta FSIN Rossii - Bulletin of the Kuzbass Institute of the Federal Penal Service of Russia, 2015, no. 3 (24), pp. 75-81. (In Russ.).

6. Oganesyan S. S., Gabaraev A. SH., Godovanec O. G., Kazberov P. N. Problemy protivodejstviya religioznomu ekstremizmu i puti formirovaniya veroterpimosti v mestah lisheniya svobody [Problems of counteracting religious extremism and ways of forming tolerance in places of deprivation of liberty]. Moscow, 2017. 168 p. (In Russ.).

7. Silant'ev R. A., Noskov V. V., Savin A. V. K probleme verbovochnoj deyatel'nosti terroristicheskih i ekstremistskih organizacij v mestah lisheniya svobody [On the problem of recruitment of terrorist and extremist organizations in prisons]. CHelovek: prestuplenie i nakazanie - Man: crime and punishment, 2017, vol. 25, no. 1, pp. 113-117. (In Russ.).

8. Ekstremizm [Extremism]. Available at: http://www.endic.ru/ozhegov/JEkstremizm-40160.html (accessed 02.04.2019). (In Russ.) 